University of Nebraska - Lincoln

DigitalCommons@University of Nebraska - Lincoln

6-1973

\title{
Tool-Making and Tool-Using in the Northern Blue Jay
}

Thony B. Jones

University of Massachusetts, Amherst

Alan Kamil

University of Nebraska - Lincoln, akamil1@unl.edu

Follow this and additional works at: https://digitalcommons.unl.edu/bioscibehavior

Part of the Behavior and Ethology Commons

Jones, Thony B. and Kamil, Alan, "Tool-Making and Tool-Using in the Northern Blue Jay" (1973). Papers in Behavior and Biological Sciences. 66.

https://digitalcommons.unl.edu/bioscibehavior/66

This Article is brought to you for free and open access by the Papers in the Biological Sciences at DigitalCommons@University of Nebraska - Lincoln. It has been accepted for inclusion in Papers in Behavior and Biological Sciences by an authorized administrator of DigitalCommons@University of Nebraska - Lincoln. 


\title{
Tool-Making and Tool-Using in the Northern Blue Jay
}

\author{
Thony B. Jones and Alan C. Kamil \\ Department of Psychology, University of Massachusetts, Amherst
}

\begin{abstract}
Laboratory-raised Northern blue jays (Cyanocitta cristata) have been observed tearing pieces from pages of newspaper and utilizing them as tools to rake in food pellets which were otherwise out of reach. The frequency of this behavior was dependent upon the motivational state of the jay and the presence of food pellets.
\end{abstract}

Tool utilization in animals may be defined as the use of physical objects other than the animal's own body or appendages as a means to extend the physical influence realized by the animal (1). Although it is possible that many species can engage in such behavior, and although a number of cases of tool use by animals including birds have been reported, there are relatively few well-documented observations (2). We report one instance of tool use which we have observed in the Northern blue jay (Cyanocitta cristata).

One adult blue jay raised in our laboratory colony was seen engaging ill the following behavioral sequence. The jay ripped a piece of newspaper from the pages kept beneath its cage, manipulated the piece of paper, and then proceeded to thrust it back and forth between the wires of its cage, raking in food pellets too distant to be picked up directly with its beak.

This blue jay was brought into the laboratory at an estimated age of 7 to 10 days from a nest in the Amherst, Massachusetts, area 16 months before our observation of its tool use. It had been hand-raised and then maintained in a 45.7 by 45.7 by $61.0 \mathrm{~cm}$ wire cage that hung from the wall on pieces of 2 by 4 inch lumber; the wood made a small ledge on top of which food pellets often collected. Pages of newspaper were kept beneath the cage to catch droppings. Three different times during the 16-month interval, once for 2 weeks and twice for 5 weeks, the jay
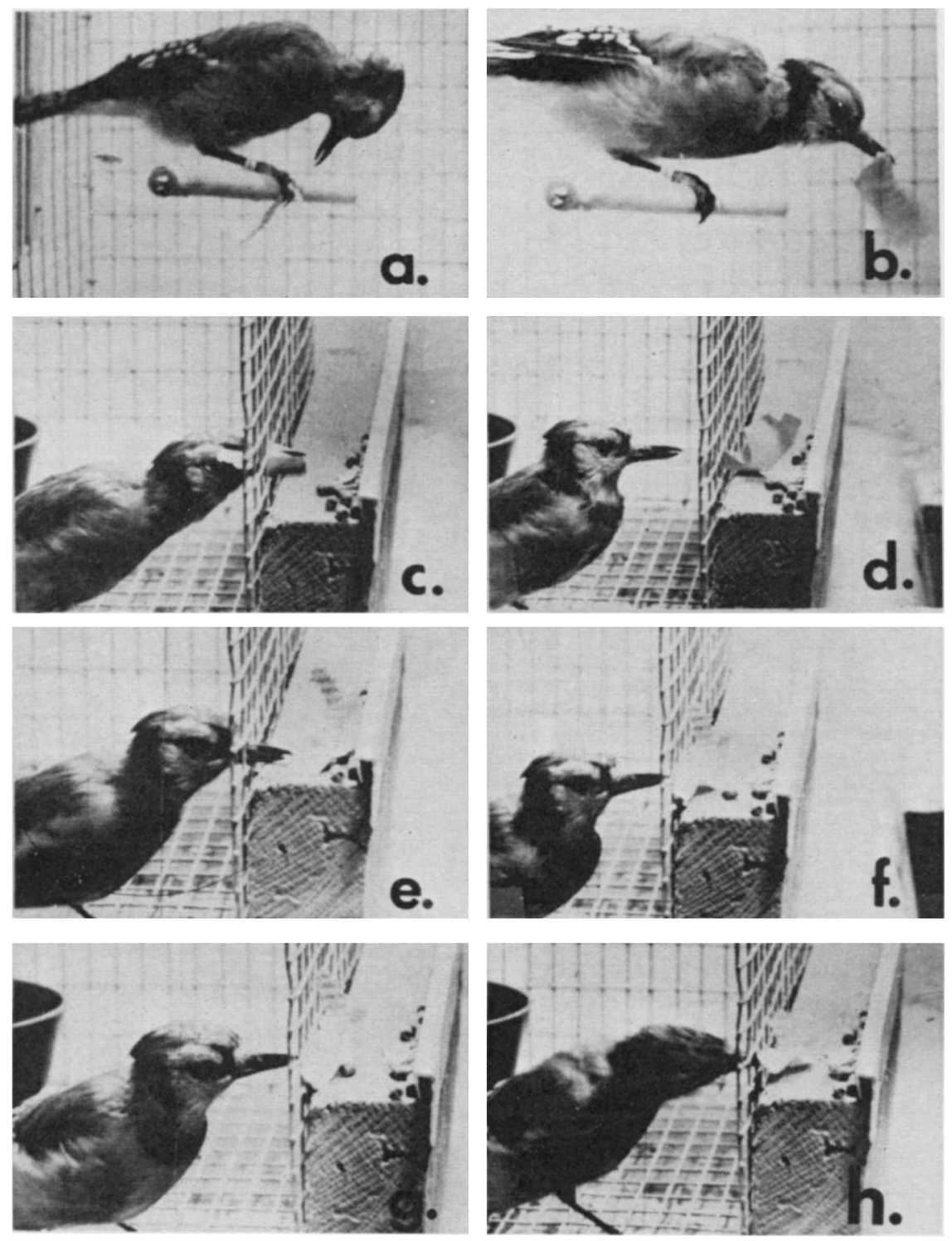

Figure 1. Typical components of the tool-using behavior taken from a sequence filmed at 16 frames per second. (a) Frame 1 . The bird is manipulating the paper on the perch. (b) Frame 13. The bird hops off the perch with paper in beak. (c) Frame 140. The paper is inserted through the wires of the cage. (d) Frame 156. The bird releases the paper and withdraws its beak. Between (d) and (e) the paper is swept from left to right with repeated grasping, moving, and releasing movements. (e) Frame 181. The paper is thrust forward and dropped on top of pellets. (f) Frame 183. The bird retracts the paper, setting a pellet in motion toward the wires of the cage. $(\mathrm{g})$ Frame 189. The paper is released to rest on top of the pellet. (h) Frame 197. The bird retracts its beak after picking up the pellet, which is visible just under the edge of the paper in (g). 


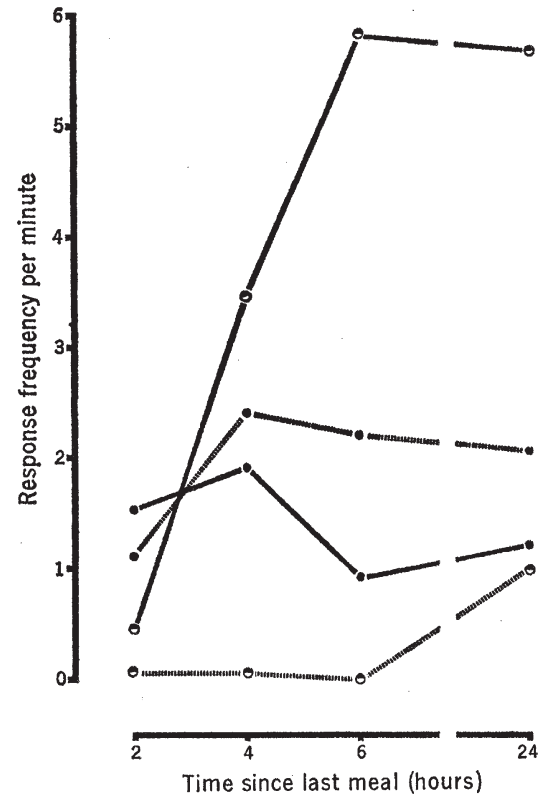

Figure 2. The frequency of tool-using behavior as a function of time since feeding. The frequency of paper manipulation (solid circles) and of thrusting the paper between the wires of the cage (divided circles ) is shown for days when pellets were present on the ledge (solid line) and for days when no pellets were present (dashed line).

was maintained on a food-deprivation schedule that consisted of one feeding daily of a small food ration. It seems a fair conclusion that the jay somehow acquired its tool-using behavior while maintained under this combination of circumstances - a food-deprivation schedule, food pellets just out of reach on the ledge, and newspaper available under its cage. We know of no reports of tool use in the wild by blue jays (3).

After we observed the jay using a tool, we isolated it from the other jays in our colony in a cage modified by replacing the wire on one end with Plexiglas. We recorded the behavior on 16-mm film. Figure 1 shows eight photographs taken from frames of a single filmed sequence. These frames illustrate some typical components of the tool- using sequence. During filming sessions, we generally presented the blue jay with a 1.9 by $5.3 \mathrm{~cm}$ piece of paper. The most common response after taking the paper was to carry it to the perch and manipulate it. This manipulation could take a number of forms: (i) holding the paper be- tween its feet and the perch and pecking at it, with the perch serving as an anvil; (ii) turning the paper a number of times by repeatedly grasping the paper in its beak and repositioning it between its feet and the perch; and (iii) holding the paper between its feet and the perch and twisting and turning it with its beak. The general results of these coordinated beak and feet manipulations was a crumpled and irregularly shaped piece of paper. Next, the jay would sometimes place the paper in its water dish. Occasionally, especially when the interval since the last feeding had been long, these manipulatory stages were absent.

The jay would then take the paper and approach the side of the cage near the ledge and use the paper to rake in pellets we had placed there. Three patterns of this behavior were observed: (i) thrusting the paper through the wires and rapidly withdrawing it and flinging it away in a continuous motion; (ii) thrusting the paper through the wires and slowly withdrawing it, grasping it in the beak for a moment and then, in a separate discrete movement, throwing it to the floor; and (iii) thrusting the paper through the wires, releasing it and withdrawing the beak, and then thrusting and grasping the paper again. The behavior sequence illustrated in Figure 1 exemplifies this third pattern. The blue jay positioned the paper on one side of the pellets and by repositioning its grip on the paper made successive sweeping movements of the paper to the opposite side of the pellets, thus sweeping pellets in an arc nearer a point where they could be reached with the beak from between the wires.

On different occasions we presented the blue jay with a feather, a 7.6- to 10.2-cm thistle, a piece of straw grass, a paper clip, and a plastic bag tie. In all cases the blue jay thrust the object between the wires and, except when using the thistle, was successful in raking in pellets.

In order to test whether this tool use was in fact a food-getting response influenced by food-related stimuli, we investigated the effects of food deprivation and presence of obtainable food pellets on this behavior. The blue jay was tested on six consecutive days. On days 1,3 , and 5 , pellets were present on the ledge behind the cage, whereas no pellets were present on days 2, 4, or 6 . Each day, the jay was observed for four 5-minute periods 2, 4, 6, and 24 hours since the last feeding. During each period, 1.9 by $5.3 \mathrm{~cm}$ pieces of paper were available, and frequencies were recorded for several behaviors: (i) manipulation of the paper with beak while holding the paper on the perch with the feet; (ii) actual tool use, defined as thrusting the paper between the wires of the cage near the pellets lying on the ledge; and (iii) the number of pellets obtained.

The frequency of tool use was virtually zero when pellets were not present, and increased as a function of deprivation when they were present, reaching asymptotic levels within 6 hours of food deprivation (Figure 2). These peak frequencies were quite high, about six per minute, and resulted in obtaining a pellet about once per minute. Some increase in frequency of tool use was also apparent under 24-hour deprivation when pellets were not present. However, of the 17 occurrences of tool use on days when pellets were absent, 14 were observed on the first such test day, 3 on the second day, and none on the third day; this suggests adaptation to the no-pellet condition. A relatively high level of manipulatory behavior was also observed, especially when pellets were not present and tool-using responses were therefore infrequent. Finally, another possible type of tool use was observed in the absence of pellets The blue jay would occasionally take the paper, drop it in its water dish, and sweep it around the food cup, picking up food-dust as if with a sponge. The jay would then either eat small pieces of dust off the paper or ingest the paper itself. This behavior was observed several times.

In an attempt to find some blue jays who had not acquired tool use in order to begin a study of acquisition of this behavior, we tested a number of the blue jays in our colony. Of eight hand-raised birds tested, all more than 1 year of age, five showed definite tool use, two displayed some components of the behavior, and only one showed no sign of tool use at all. Even this single jay showed a high level of manipulation of the paper. 
How the tool-using behavior first arose in our colony remains an important question. Although a definitive answer is not possible, we feel that the behavior was first acquired serendipitously by a single blue jay. We have often informally observed that blue jays will engage in a wide range of general exploratory behaviors, including manipulatory and probing movements, with any small object available. If, during such a sequence of apparently undirected behavior, a food pellet were accidentally obtained, this would probably result in an increase in the likelihood of repetition of the responses that immediately preceded obtaining the food pellet. These conditions would be sufficient to produce a kind of trial-and-error learning. The fact that to date we have found six jays in our colony demonstrating tool-using behavior is thought to be more likely the result of the spread of the behavior through observational learning or imitation than the result of the independent acquisition of this behavior by each of the six jays.
As Hall (1) correctly indicated, tool use in animals has received unwarranted attention because of its superficial similarity to human tool use. However, tool use is important as one of a number of indices of the type of behavioral adaptations characteristic of a species, even when observed in a laboratory setting. In the present case, it is clear that we have observed a learned behavioral sequence involving toolmaking (in the tearing and alteration of paper) and tool use. This behavior is flexible with regard to the objects that can be successfully employed and has spread to a number of blue jays in our colony. Thus, the acquisition of tool use exhibited by blue jays, especially when taken together with other indices such as the performance of blue jays on learning-set tasks (4), may be indicative of a particular potential for behavioral adaptations typical of some species with highly generalized feeding behaviors, such as the Northern blue jay.

\section{References and Notes}

1. K. R. L. Hall, Curr. Anthropol. 4, 479 (1963).

2. Specific examples of tool use by birds: A. Alcock, Ibid. 112, 542 (1970); A. H. Chisholm, ibid. 96, 380 (1954); D. Lack, Sci. Amer. 188, 66 (April 1953); H. B. Lovell, Wilson Bull. 70, 280 (1957); G. C. Milliken and R. I. Bowman, Living Bird 6, 23 (1967); J. van Lawick-Goodall, Nature 212, 1468 (1966); J. van Lawick-Goodall and H. van Lawick, Nat. Geogr. Mag. 133, 631 (1968). General reviews of the tool-using literature: Hall (1); J. Alcock, Evolution 26, 464 (1972); J. van LawickGoodall, Advan. Study Behav. 3, 195 (1970); W. H. Thorpe, Learning and lnstinct in Animals (Harvard Univ. Press, Cambridge, 1963).

3. A. C. Bent, Life Histories of North American Jays, Crows and Titmice (Bulletin 191, Smithsonian Institution, United States National Museum, Washington, D.C., 1946); J. W. Hardy, Univ. Kans. Sci. Bull. 42, 13 (1961).

4. M. W. Hunter and A. C. Kamil, Psychonom. Sci. 22, 271 (1971); A. C. Kamil, M. Lougee, R. I. Shulman, J. Comp. Physiol. Psychol. 82, 394 (1973).

5. We thank Saul Balagura and Theodore Sargent for their critical comments on an earlier version of the report. Supported by NSF grant GB-30501 to A.C.K. 